\title{
Effects of Basic Training in the British ARMy on Regular and Reserve Army Personnel
}

\author{
Alum G. Williams \\ Institute for Biophysical and Clinical Research Into Human Movement, Manchester Metropolitan University, \\ Alsager, United Kingdom.
}

\begin{abstract}
Williams, Alun G. Effects of Basic Training in the British Army on Regular and Reserve Army Personnel. J. Strength Cond. Res. 19(2):254-259. 2005.-The aim of this study was to compare changes in aerobic fitness and body composition in response to British Army (regular) and Territorial Army (reserve) basic training. Eleven regular recruits, 14 reserve recruits, and 20 controls completed the study (all males). Initially, reserve recruits were significantly older and heavier and had greater fat-free mass (FFM; 64.6 vs. $59.3 \mathrm{~kg}$ ) and lower maximal oxygen uptake $\left(\mathrm{V}_{\mathrm{O}_{2}} \mathrm{max} ; 39.1 \mathrm{vs} .43 .9 \mathrm{ml} \cdot \mathrm{kg}^{-1} \cdot \mathrm{min}^{-1}\right)$ than regular recruits. Both regular and reserve training significantly increased FFM and $\mathrm{VO}_{2}$ max and decreased percentage body fat. Regular training produced a greater increase in $\mathrm{VO}_{2}$ max than reserve training (13.1 vs. $7.6 \%, p<0.0005)$. Reserve training produced a greater increase in body mass $(2.2 \mathrm{vs} .0 .9 \mathrm{~kg}, p=$ $0.019)$ and tended to produce a greater increase in FFM (2.6 vs. $1.6 \mathrm{~kg}, p=0.062$ ). Although both training programs improve aerobic fitness and body composition, increasing the volume of physical training in the reserve training program would probably enhance the training adaptations achieved.
\end{abstract}

Key Words. Aerobic fitness, body composition, military personnel

\section{INTRODUCTION}

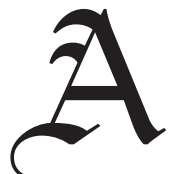

rmy forces typically consist of both regular and reserve personnel. Regular army soldiers work full time in the military and undergo sustained initial basic training and usually further intermittent occupational training. Reserve army soldiers are either former regular soldiers or new recruits who undergo initial basic training and usually further intermittent military training. Reserve army soldiers typically have primary employment outside the military and often become "full-time" soldiers only when called on during times of conflict-for example, British (Territorial Army) and U.S. forces during the recent Iraq conflict (4).

Because of the physically demanding nature of soldiering $(2,11,18)$, physical training is an important feature of military training. In military organizations, initial basic training is intended to give army recruits both the necessary skills and the physical fitness required for their future careers (13). High aerobic fitness, FFM, muscle strength, and low percentage body fat (\% fat) are desirable physical fitness characteristics for army soldiers, as these characteristics have been related to performance ability in common military tasks such as marching long distances with considerable backpack loads $(5,17)$, maximal (17) and repetitive (12) box lifting, and stretcher carrying (19). Accordingly, basic training for male regular soldiers has generally been shown to produce significant increases in maximal oxygen uptake $\left(\mathrm{V}_{2} \max \right)(7,10,14$,
$22,23)$ and favorable changes in $\%$ fat and $\operatorname{FFM}(6,22$, 23 ), although relatively small changes in muscle strength have been observed $(6,10,23)$. However, even the most recent report of British Army basic training for male regular soldiers (23) is now somewhat dated, as British Army basic training has been extended by 1 week to 12 weeks duration and its content altered since data collection in 1997.

Reserve army soldiers are expected to perform tasks equivalent to regular soldiers of the same rank and specialty. However, basic training for U.K. reserve recruits is conducted separately from regular recruits and is typically based around 3-day "training weekends." Furthermore, in contrast to regular soldiers, relatively little published research has investigated the changes in physical fitness brought about by basic training for reserve army soldiers, and none has done so for U.K. reserve recruits. Thus, the purpose of the present study was to compare the changes in aerobic fitness and body composition in response to British Army (regular) initial basic training and Territorial Army (reserve) initial basic training. It was hypothesized that the continuous nature of the regular basic training program would produce greater improvements in aerobic fitness and body composition than the intermittent reserve basic training program.

\section{Methods}

\section{Experimental Approach to the Problem}

Two groups of military recruits were assessed for aerobic fitness and body composition before and after undergoing their respective army initial basic training programs. One group was from the Territorial Army (reserve group) and the other from the British Army (regular group). The training programs used were not altered in any way for the purpose of this study. A separate control group was also used to assess any learning effects of the pretraining test procedures on posttraining test performance. All data were collected during 2001. The Sport, Health and Exercise ethics committee at Staffordshire University, United Kingdom, approved the study, and written informed consent was obtained from all subjects.

\section{Subjects}

Nineteen male British Army recruits (age, $18 \pm 1$ year; body mass, $67.9 \pm 5.3 \mathrm{~kg}$; stature, $1.76 \pm 0.06 \mathrm{~m}$; body mass index [BMI], $22.0 \pm 2.1 \mathrm{~kg} \cdot \mathrm{m}^{-2}$; physical activity, $1.5 \pm 1.2 \mathrm{~h}$ per week; mean $\pm S D$ ) from the Army Training Regiment at Lichfield, United Kingdom, formed the regular group, none of whom had been back-squadded from other platoons or had any other previous military experience. Twenty male Territorial Army recruits (age, 
$23 \pm 5$ years; body mass, $76.1 \pm 13.2 \mathrm{~kg}$; stature, $1.78 \pm$ $0.08 \mathrm{~m}$; BMI, $24.0 \pm 4.3 \mathrm{~kg} \cdot \mathrm{m}^{-2}$; physical activity, $1.3 \pm$ $1.4 \mathrm{~h} \cdot \mathrm{wk}^{-1}$ ) from the Nesscliff Training Camp, Shrewsbury, United Kingdom, and the Birmingham Fusiliers TA Centre, Birmingham, United Kingdom, formed the reserve group, none of whom had been back-squadded from other platoons or had any other previous military experience. Twenty recreationally active male university students (age, $20 \pm 2$ years; body mass, $74.6 \pm 8.6 \mathrm{~kg}$; stature, $1.78 \pm 0.07 \mathrm{~m}$; BMI, $23.5 \pm 1.8 \mathrm{~kg} \cdot \mathrm{m}^{-2}$; physical activity, $1.8 \pm 1.5 \mathrm{~h} \cdot \mathrm{wk}^{-1}$ ) from Staffordshire University, United Kingdom, formed the control group. Nine regular subjects $(47 \%)$ and 6 reserve subjects $(30 \%)$ either left training (for voluntary or other reasons) or were backsquadded to other platoons because of injury or substandard performance in tests of military skills or knowledge (thereby increasing the duration of their training).

\section{Measurements}

For all subjects, tests were performed on a single day in the week prior to and in the final week of the 12 -week training program/control period in large, well-ventilated gymnasia. All military subjects wore identical military PT kit, while the control group also wore shorts, lightweight shirt, and training shoes. All subjects were asked to refrain from strenuous exercise in the 48 hours prior to each testing day, and military instructors also cooperated in allowing this. Body mass (Seca scales; Cranlea, Birmingham, UK) and stature were assessed using portable instruments calibrated against previously calibrated laboratory instruments. Percentage body fat was estimated using a tetrapolar electrical impedance device (Bodystat 1500; Bodystat Ltd., Douglas; Isle of Man; UK), according to the manufacturer's instructions. The electrical impedance device was used before exercise testing, after subjects had been supine for 5 minutes. Fat-free mass (FFM) was calculated as the difference between body mass and fat mass. $\mathrm{V}_{2}$ max was then estimated using a progressive 20-m multistage shuttle run test (16). In this maximal effort test, running speed is increased progressively as subjects attempt to complete each $20-\mathrm{m}$ interval before the sounding of a "bleep" from a CD player. If a subject fails to complete the required distance in the time available, then initially 2 further attempts are allowed to try to regain the required speed before the test is terminated. Duration of running was recorded in seconds, and predictions of $\mathrm{VO}_{2}$ max in $\mathrm{ml} \cdot \mathrm{kg}^{-1} \cdot \mathrm{min}^{-1}$ were obtained using a conversion table for running time to $\mathrm{V}_{2} \max (16)$. These predicted data were also used to express $\dot{\mathrm{V}}_{2}$ max in $\mathrm{L} \cdot \mathrm{min}^{-1}$ and $\mathrm{ml} \cdot \mathrm{kg}^{-2 / 3} \cdot \mathrm{min}^{-1}$ by using the body mass data. On the first test day, subjects were also asked to estimate the mean time per week spent in "moderate and vigorous physical activity" during the previous 4 weeks. In addition, reserve subjects were asked to keep a training log during the training period of moderate and vigorous physical activity conducted outside their scheduled training program. The training logs were collected from the reserve group on the posttraining test day.

\section{Training}

The control group was asked to continue with habitual physical activity patterns, while the regular and reserve groups underwent their respective 12 -week basic training programs. For the regular group, 90 periods of 40 minutes within the first 11 weeks of training were used specifi- cally for physical training. These 90 periods consisted of sports (23 periods), circuit training (22 periods), endurance (13 periods), agility (12 periods), swimming (9 periods), material handling (3 periods), and fitness monitoring sessions ( 8 periods). For the reserve group, 10 periods of 45 minutes within the first 11 weeks of training (during 5 training weekends) were used specifically for physical training, consisting of endurance ( 8 periods) and agility ( 2 periods). Sports periods were typically team ball games in a small area. Endurance periods typically involved running in groups for $>10$ minutes and occasionally involved load carriage with up to $16 \mathrm{~kg}$. Agility periods included gymnasium work using benches and ropes as well as assault course practice. Material handling periods included mainly tuition in a recommended safe technique. Circuit training periods were somewhat variable in content but generally consisted of high-repetition, lowforce exercises using all major muscle groups and exercise: rest periods of approximately 30:10 seconds. A typical circuit training session included a number of exercises, such as shuttle runs, press-ups, squat thrusts, barbell curls, supported dips from a bench, star jumps, sit-ups, and bench steps, but the modes of exercises used varied between sessions. The reserve group also reported a mean $\pm S D$ of $2.0 \pm 1.5 \mathrm{~h} \cdot \mathrm{wk}^{-1}$ of physical activity conducted outside their scheduled training program, half of which was categorized as "strength training" and the remainder "endurance training."

In addition to physical training, both military training programs included other physical exercise, such as prolonged marching with various loads while on military exercise, and many periods of drill practice that averaged about 1 40-minute period per day for the regular group but consisted mainly of 22 -hour periods within the first 4 weeks for the reserve group. The total organized training and additional exercises are listed in Table 1 for comparison.

\section{Statistical Analyses}

Baseline characteristics were compared between groups using 1-way analysis of variance (ANOVA) and NewmanKeuls post hoc tests. All baseline characteristics were also compared directly between regular and reserve groups using 2-tailed unpaired $t$-tests. Differences between preand posttraining values within each group were analyzed using 2-tailed paired $t$-tests. The effects of training were compared between all 3 groups and directly between regular and reserve groups, using repeated measures analysis of covariance (ANCOVA), with pretraining values of age and the specific variable being analyzed entered as covariates. Statistical significance was set at the 0.05 level.

\section{RESULTS}

Before training, ANOVA revealed no significant differences among the 3 groups in terms of stature, BMI, \% fat or $\dot{\mathrm{V}}_{2} \mathrm{max}$ expressed in either $\mathrm{L} \cdot \mathrm{min}^{-1}$ or $\mathrm{ml} \cdot \mathrm{kg}^{-2 / 3} \cdot \mathrm{min}^{-1}$ (Table 2). The reserve group was significantly older than both the regular $(p<0.0005)$ and the control $(p=0.015)$ groups and had greater mass $(p=0.017)$ and FFM $(p=$ $0.017)$ and lower $\dot{\mathrm{VO}}_{2} \max$ expressed in $\mathrm{ml} \cdot \mathrm{kg}^{-1} \cdot \mathrm{min}^{-1}(p$ $=0.007)$ and $\mathrm{ml} \cdot \mathrm{kg}^{-2 / 3} \cdot \mathrm{min}^{-1}(p=0.043)$ than the regular group (Table 2 and Figure 1).

Stature did not change significantly for any of the groups during the 12-week period (data not shown), nor 
TABLE 1. Major characteristics of the organized training and additional exercises performed by the regular and reserve recruits and control subjects. Refer to text for further details.

\begin{tabular}{|c|c|c|c|}
\hline & Regular* & Reserve & Control \\
\hline Organized training & $\begin{array}{l}90 \times 40 \text {-min periods in } 11 \mathrm{wk} \\
(\text { total }=3,600 \mathrm{~min}) \\
26 \% \text { sports } \\
24 \% \text { circuit training } \\
14 \% \text { endurance } \\
13 \% \text { agility } \\
10 \% \text { swimming } \\
3 \% \text { material handling } \\
9 \% \text { monitoring of fitness }\end{array}$ & $\begin{array}{l}10 \times 45 \text {-min periods in } 11 \\
\text { wk concentrated in } 5 \\
\text { training weekends } \\
\text { (total }=450 \mathrm{~min}) \\
80 \% \text { endurance } \\
20 \% \text { agility }\end{array}$ & None \\
\hline Additional exercise & $\begin{array}{l}\text { Drill practice } \\
\text { Military field exercise }\end{array}$ & $\begin{array}{l}\text { Drill practice } \\
\text { Military field exercise } \\
2.0 \pm 1.5 \mathrm{~h} \cdot \mathrm{wk}^{-1} \text { personal } \\
\text { training } \\
\sim 50 \% \text { strength } \\
\sim 50 \% \text { endurance }\end{array}$ & $\begin{array}{l}\text { Continue with habitual } \\
\text { physical activity } \\
\left(1.8 \pm 1.5 \mathrm{~h} \cdot \mathrm{wk}^{-1}\right)\end{array}$ \\
\hline
\end{tabular}

* Percentage data do not total $100 \%$ because of rounding.

TABLE 2. Mean $\pm S D$ subject characteristics on entry to army basic training for regular and reserve recruits and control subjects.

\begin{tabular}{|c|c|c|c|c|}
\hline & $\begin{array}{l}\text { Regular } \\
(n=19)\end{array}$ & $\begin{array}{l}\text { Reserve } \\
(n=20)\end{array}$ & $\begin{array}{c}\text { Control } \\
(n=20)\end{array}$ & $\begin{array}{c}p \\
\text { (ANOVA)* }\end{array}$ \\
\hline Age (y) & $18 \pm 1 \dagger \ddagger$ & $23 \pm 5 \dagger+$ & $20 \pm 2$ & $<0.0005$ \\
\hline Mass (kg) & $67.9 \pm 5.3+\neq$ & $76.1 \pm 13.2$ & $74.6 \pm 8.6$ & 0.025 \\
\hline Body mass index $\left(\mathrm{kg} \cdot \mathrm{m}^{-2}\right)$ & $22.0 \pm 2.1$ & $24.0 \pm 4.3$ & $23.5 \pm 1.8$ & 0.099 \\
\hline Body fat $(\%)$ & $12.4 \pm 3.8$ & $14.5 \pm 4.5$ & $15.3 \pm 3.0$ & 0.060 \\
\hline$\dot{\mathrm{V}}_{2} \max \left(\mathrm{L} \cdot \min ^{-1}\right)$ & $2.98 \pm 0.33$ & $2.95 \pm 0.57$ & $3.09 \pm 0.54$ & 0.629 \\
\hline$\dot{\mathrm{VO}}_{2} \max \left(\mathrm{ml} \cdot \mathrm{kg}^{-2 / 3} \cdot \min ^{-1}\right)$ & $179.0 \pm 18.1 \ddagger$ & $164.5 \pm 24.4$ & $174.2 \pm 22.4$ & 0.117 \\
\hline
\end{tabular}

* ANOVA $=$ analysis of variance.

$\uparrow$ Significantly different from control.

\$ Significantly different from reserve.

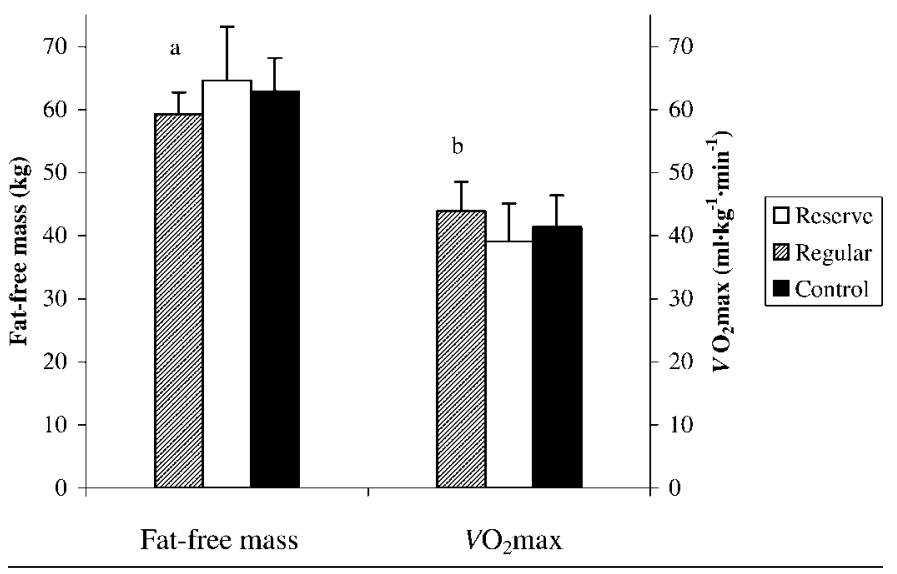

Figure 1. Fat-free mass (FFM; kg) and $\dot{\mathrm{VO}}_{2} \max$ $\left(\mathrm{ml} \cdot \mathrm{kg}^{-1} \cdot \mathrm{min}^{-1}\right)$ on entry to army basic training for regular $(n$ $=19)$ and reserve $(n=20)$ recruits and control subjects $(n=$ $20)$. a $=$ Regular FFM significantly different from reserve ( $p=$ 0.017 ) and control ( $p=0.016) . \mathrm{b}=$ Regular $\dot{\mathrm{V}}_{2} \max$ significantly different from reserve $(p=0.007)$. Data are mean $\pm S D$.

was there any difference in change between groups (ANCOVA training $\times$ group interaction $p=0.509$ ). There was no statistically significant change in any of the variables measured for the control group (Table 3). For the regular group, training produced a significant reduction in \% fat and significant increases in FFM and $\dot{V}_{2}$ max expressed in $\mathrm{L} \cdot \mathrm{min}^{-1}, \mathrm{ml} \cdot \mathrm{kg}^{-1} \cdot \mathrm{min}^{-1}$, and $\mathrm{ml} \cdot \mathrm{kg}^{-2 / 3} \cdot \mathrm{min}^{-1}$ (Table 3). For the reserve group, training produced significant increases in mass, FFM, and $\mathrm{VO}_{2}$ max expressed in L.min ${ }^{-1}$, $\mathrm{ml} \cdot \mathrm{kg}^{-1} \cdot \mathrm{min}^{-1}$, and $\mathrm{ml} \cdot \mathrm{kg}^{-2 / 3} \cdot \mathrm{min}^{-1}$ (Table 3 ).

ANCOVA showed that FFM (training $\times$ group interaction $p<0.0005$ ) increased in response to both regular $(p=0.018)$ and reserve $(p<0.0005)$ training relative to the control group. Similarly, $\dot{\mathrm{V}}_{2} \mathrm{max}$ expressed in $\mathrm{L} \cdot \mathrm{min}^{-1}, \mathrm{ml} \cdot \mathrm{kg}^{-1} \cdot \mathrm{min}^{-1}$, and $\mathrm{ml} \cdot \mathrm{kg}^{-2 / 3} \cdot \mathrm{min}^{-1}$ (all training $\times$ group interactions $p<0.0005$ ) increased in both the regular (all $p<0.0005$ ) and the reserve $(p=0.001, p=$ 0.039 , and $p=0.010$ for $\mathrm{L} \cdot \mathrm{min}^{-1}, \mathrm{ml} \cdot \mathrm{kg}^{-1} \cdot \mathrm{min}^{-1}$, and $\mathrm{ml} \cdot \mathrm{kg}^{-2 / 3} \cdot \mathrm{min}^{-1}$, respectively) groups relative to the control group. Percentage body fat (training $\times$ group interaction $p=0.007)$ decreased in both the regular $(p=$ $0.034)$ and the reserve ( $p=0.046)$ groups relative to the control group. Mass and BMI (both training $\times$ group interactions $p=0.001$ ) increased in the reserve group relative to the control group (both $p<0.0005$ ), with no significant difference between the changes in the regular and control groups $(p=0.156$ and $p=0.432$ for mass and BMI, respectively). Percentage changes in all variables for all 3 groups are shown in Figure 2.

Direct comparisons between regular training and reserve training revealed that regular training produced significantly greater increases than reserve training in $\mathrm{V}_{2} \max$ expressed in $\mathrm{ml} \cdot \mathrm{kg}^{-1} \cdot \mathrm{min}^{-1}(p<0.0005)$ and 
TABLE 3. Subject characteristics before (Pre) and after (Post) the intervention period for regular $(n=11)$ and reserve $(n=14)$ recruits and control $(n=20)$ subjects.

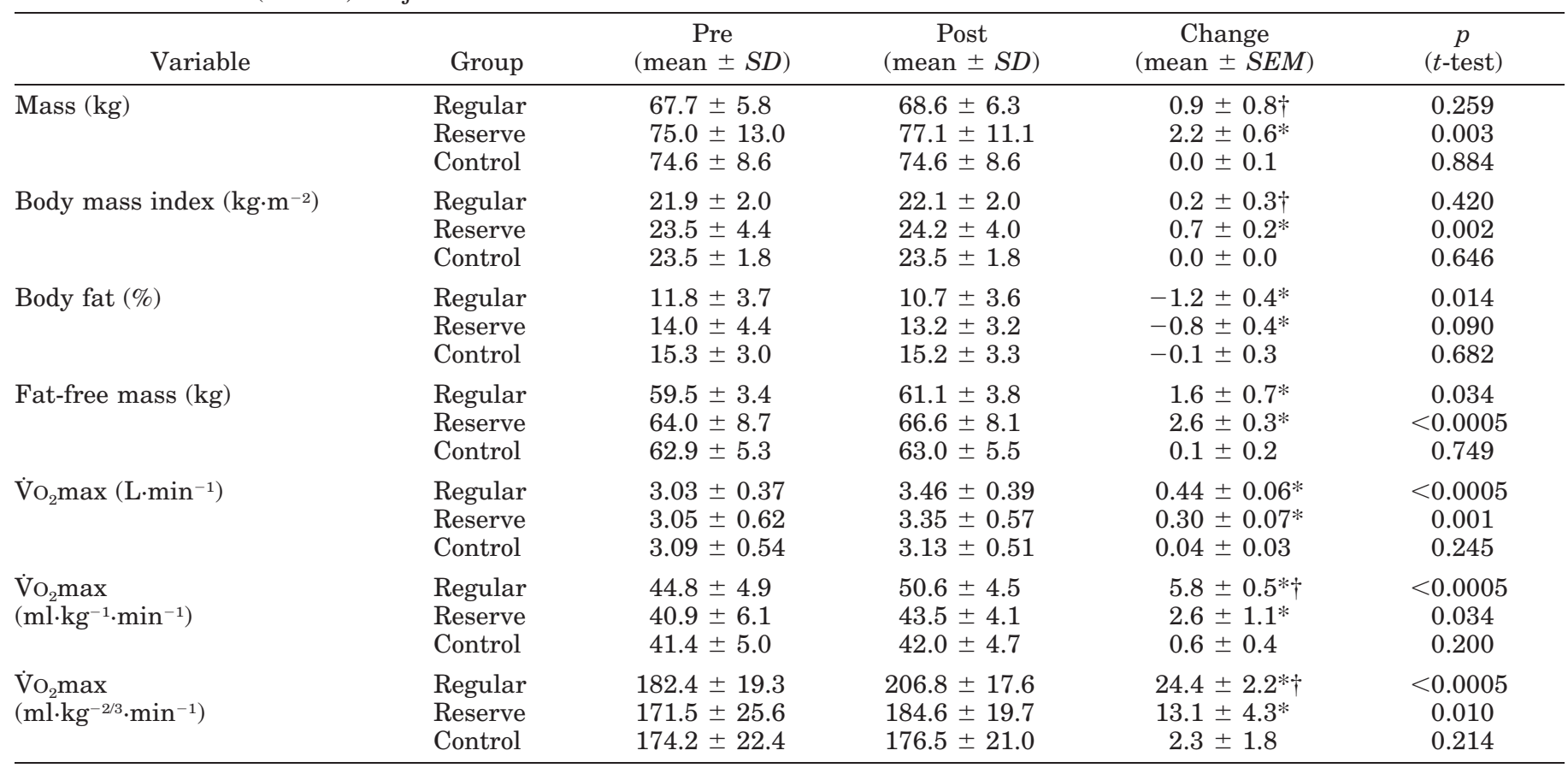

* Significantly different from control.

$\dagger$ Significantly different from reserve.

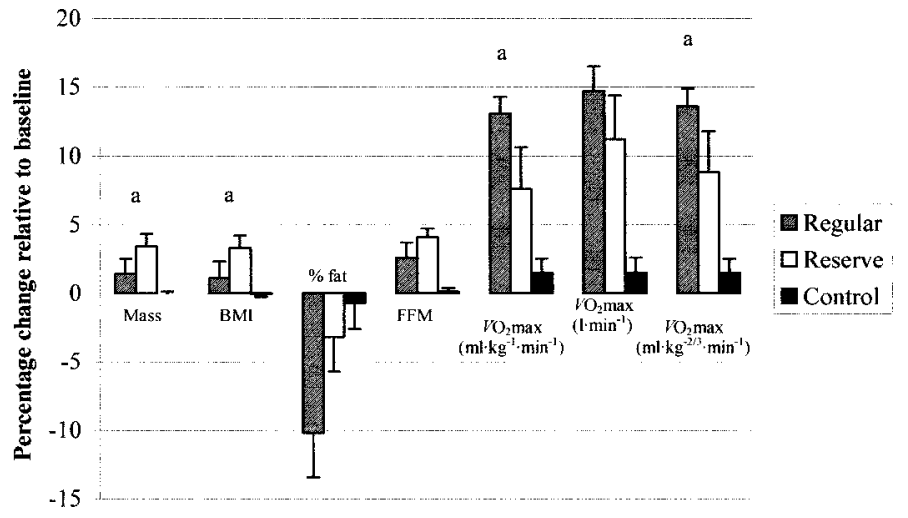

FIGURE 2. Percentage change in body mass, body composition, and $\mathrm{V}_{2}$ max during the intervention period for regular $(n=11)$, reserve $(n=14)$, and control $(n=20)$ subjects. $a=$ Regular significantly different from reserve. All reserve data significantly different from control. Regular data significantly different from control for all variables except mass and body mass index (BMI). Data are mean $\pm S E M$.

$\mathrm{ml} \cdot \mathrm{kg}^{-2 / 3} \cdot \mathrm{min}^{-1}(p=0.003)$ and tended to produce a greater decrease in $\%$ fat $(p=0.065)$ and a greater increase in $\mathrm{V}_{2}$ max expressed in $\mathrm{L} \cdot \mathrm{min}^{-1}(p=0.170)$. Reserve training produced significantly greater increases than regular training in body mass $(p=0.019)$ and $\mathrm{BMI}(p=$ $0.026)$ and tended to produce a greater increase in FFM $(p=0.062)$.

\section{Discussion}

During their 12-week period of basic training, British reserve (Territorial Army) recruits improved their fitness profiles in terms of aerobic fitness and body composition (Figure 2). $\mathrm{V}_{2}$ max improved significantly by $11.2 \%$ with- out scaling for body mass and by $7.6-8.8 \%$ when scaled to body mass. Percentage body fat significantly decreased by $3.2 \%$ relative to baseline, and FFM increased by $4.1 \%$. These are the first reported data on changes in aerobic fitness and body composition during U.K. reserve army initial basic training. The changes reported are not only statistically significant but also important in terms of military performance because aerobic fitness and body composition have been related to performance ability on several common military tasks $(5,12,17,19)$. Unfortunately, we were not able to measure another important aspect of military fitness: muscle strength.

As hypothesized, the regular army basic training program produced a greater increase in aerobic fitness (13.1$14.7 \%$, depending on use of scaling) and tended to produce a greater decrease in $\%$ fat $(10.2 \%$ relative to baseline) than the reserve training. This is probably due to the 8fold difference in scheduled physical training time between the 2 training programs -90 periods of 40 minutes (3,600 minutes total) for regular training in comparison to 10 sessions of 45 minutes (450 minutes total) for reserve training. However, the differences in training responses to the regular and reserve training programs were obviously far less than the 8-fold difference in scheduled training time and closer to 2-3-fold. Furthermore, the reserve training produced, unexpectedly, a greater increase in FFM than the regular training, which approached statistical significance (4.1 vs. $2.6 \%$ ).

The apparent mismatch between the scheduled training time and the physiological responses of the regular and reserve groups may be explained in 3 possible ways. First, the differing status of the recruits before training may have played a role. Reserve recruits were significantly older and heavier and had greater FFM and lower $\mathrm{V}_{2}$ max scaled for body mass than the regular recruits. 
If one assumes an inverse relationship between pretraining status and the training response (20), the lower $\dot{\mathrm{V}}_{2}$ max of the reserve group may have provided more potential for improvement. However, the greater FFM of the reserve group before training would not have been expected to predispose that group to the greater increase in FFM that was observed. Furthermore, age and pretraining performance were used as covariates in the comparisons of the training responses between groups and were thus extremely unlikely to influence the outcomes of the hypothesis testing.

Second, the reserve physical training program may have been better designed than the recruit training, making more effective use of the available training time. The ratio of 8:13 for endurance training periods for reserve: regular training is comparable to the relative increases in aerobic fitness observed for the 2 groups. In this respect, the other 77 periods of the regular training (i.e., mixed-intensity sessions such as sports, circuit training, and agility) may have provided relatively little extra improvement in aerobic fitness as measured by the incremental running test. The greater differences between groups (approximately 3 -fold) in the response to training of $\%$ fat and body mass may reflect the fact that many training periods of the regular program (including sports, circuit training, and agility) are likely to have contributed to an increased total energy expenditure and possibly increased fat catabolism. Furthermore, it is possible that greater metabolic demands of the regular training program altered the hormonal environment (1) and thus limited the gain in $\operatorname{FFM}(3,8)$.

Third, the regular recruits had little opportunity to conduct targeted physical training outside the scheduled physical training sessions. Indeed, a mean scheduled training time of approximately $5.5 \mathrm{~h} \cdot \mathrm{wk}^{-1}$ is a considerable increase in training volume for a group with pretraining physical activity of approximately $1.5 \mathrm{~h} \cdot \mathrm{wk}^{-1}$. In contrast, the mean scheduled training time of the reserve recruits was just $41 \mathrm{~min} \cdot \mathrm{wk}^{-1}$, and they were specifically encouraged by the military training staff (as is usual) to also conduct their own physical training (which was reported to be approximately $2 \mathrm{~h} \cdot \mathrm{wk}^{-1}$ ) between the 5 training weekends. Thus, the difference in total training volume between the regular and reserve groups during their respective training programs was probably closer to a 2fold difference, not 8-fold, as the scheduled time for physical training would imply. Furthermore, the greater increase in FFM of the reserve group relative to the regular group corresponds with the $1 \mathrm{~h} \cdot \mathrm{wk}^{-1}$ of strength training reported by the reserve group. Notably, the regular training program included no strength training. The benefits of including strength training in British Army regular basic training have been reported since the data collection of the present study (24).

Varied methods of body fat estimation make direct comparisons between the present study and some previous studies of male army recruits $(6,14,22)$ difficult. However, the decrease in $\%$ fat of $1.2 \%$ (10.2\% relative to baseline) in regular recruits in the current study is somewhat smaller than reported previously using the same method (23). However, the present study also reported an increase in body mass for the regular group compared to a decrease previously (23) and a $2.6 \%$ increase in FFM compared to $1.2 \%$ previously (23). A 1 -week-longer training program in the current study and local factors such as military instruction technique and nutritional availability may have contributed to the differences between studies.

Similarly, varied methods of $\mathrm{V}_{2}$ max estimation make direct comparisons between the present study and some previous studies of male army recruits $(7,10,14,22)$ difficult. Nevertheless, the improvement in $\mathrm{V}_{2}$ max expressed in $\mathrm{ml} \cdot \mathrm{kg}^{-1} \cdot \mathrm{min}^{-1}$ observed in the present study is relatively high in comparison with the previous research. Williams et al. (23) used the same method of $\mathrm{VO}_{2}$ max estimation and reported an increase of $5.7 \%$, although a significantly higher pretraining mean value of 50.3 $\mathrm{ml} \cdot \mathrm{kg}^{-1} \cdot \mathrm{min}^{-1}$ in the earlier study may explain the difference with the present study $\left(43.9 \mathrm{ml} \cdot \mathrm{kg}^{-1} \cdot \mathrm{min}^{-1}\right.$ before training, improvement with training 13.1\%). The use of a control group in the present study would suggest that the relatively large increase observed was not due to a learning effect from the pretraining test session. Collectively, these data suggest that the fitness of British Army recruits when they begin training may be decreasing, although our data (i.e., 19 regular recruits in the current study) are insufficient for an appropriate cross-sectional comparison with historical data. A recent larger-scale study has shown that the pretraining $\dot{\mathrm{VO}}_{2} \max$ of U.S. Army recruits in 1998 was comparable to that of 1978 and 1983 recruits (21), and a similar evaluation of British Army recruits would be useful.

Further regarding $\dot{\mathrm{V}}_{2} \mathrm{max}$, it is interesting that the regular group showed significantly greater increases than the reserve group when the data were scaled to body mass but not when the data were expressed in units of $\mathrm{L} \cdot \mathrm{min}^{-1}$ $(p=0.170)$, although there was still a tendency for the regular group to show greater increases. When substantial external loads are added to an individual, as in the common military task of load carriage, measurements of $\mathrm{VO}_{2}$ max expressed in units of $\mathrm{L} \cdot \mathrm{min}^{-1}$ may be more predictive of performance than the common technique of dividing oxygen uptake by body mass (17). Thus, the reserve training program appears to improve this measure of aerobic fitness related to load carriage performance almost as much as the regular training. However, it is also important to appreciate that improvements in load carriage ability have recently been linked to improvements in muscle strength for initially relatively weak military recruits, whereas only the relatively strong military recruits seem to benefit most from endurance-based training (25). Individualized training prescription within military organizations would ultimately be the most fruitful approach.

In conclusion, this study has demonstrated that both the regular (British Army) and the reserve (Territorial Army) basic training programs produce favorable improvements in aerobic fitness and body composition. The regular training program produced greater improvements in aerobic fitness and tended to produce greater reductions in reducing body fat, whereas the reserve training tended to produce greater increases in FFM. Potential improvements to the British reserve initial basic training program should be investigated via an increase in training volume. In addition, future research should compare the abilities of regular and reserve recruits on material handling tasks that require muscular strength as well as endurance, as these represent many of the tasks that soldiers encounter in their military careers. 


\section{Practical Applications}

Potential improvements to the British reserve initial basic training program, such as increasing the volume of organized endurance and strength training, should be investigated. For example, integration of the regular and reserve training systems within the British Army, as in the U.S. Army, may increase the responses of reserve soldiers to basic training. Alternatively, following basic training, extra physical training and educational interventions in reserve components of the army may be required to improve physical fitness. Such initiatives have proved partially successful in improving fitness profiles of serving soldiers in the U.S. Army $(9,15)$. These sorts of initiatives may be even more applicable to British reserve forces, given the intermittent nature of the initial basic training and the relatively small improvements in aerobic fitness and \% fat observed here. Ultimately, however, an individualized approach to training prescription within military organizations, both at basic training and at post-basic training stages, would arguably be the most effective.

\section{REFERENCES}

1. Chicharro, J.L., L.M. Lopez-Mojares, A. Lucia, M. Perez, J. Alvarez, P. Labanda, F. Calvo, and A.F. Vaquero. Overtraining parameters in special military units. Aviat. Space Environ. Med. 69:562-568. 1998.

2. DUBIK, J.M., AND T.D. FulleRTON. Soldier overloading in Grenada. Mil. Rev. 67:38-47. 1987.

3. FLORINI, J.R. Hormonal control of muscle growth. Muscle Nerve 10:577-598. 1987.

4. Hoon, G. (Secretary of State for Defence). Iraq: Contingency Preparations Update. London: U.K. Parliament, House of Commons Official Report (Hansard), January 7, 2003.

5. KNAPIK, J., E. HARMAN, AND K. REYNOLDS. Load carriage using packs: A review of physiological, biomechanical and medical aspects. Appl. Ergon. 27:207-216. 1996.

6. KNAPIK, J.J., J.E. WRIGHT, D.M. KowAL, AND J.A. Vogel. The influence of U.S. Army basic initial entry training on the muscular strength of men and women. Aviat. Space Environ. Med. 51:1086-1090. 1980.

7. Kowal, D.M., J.F. Patton, AND J.A. Vogel. Psychological states and aerobic fitness of male and female recruits before and after basic training. Aviat. Space Environ. Med. 49:603606. 1978.

8. Kraemer, W.J., J.F. Patton, S.E. Gordon, E.A. Harman, M.R. Deschenes, K. Reynolds, R.U. Newton, N.T. TRIPlett, AND J.E. DzIADOS. Compatibility of high-intensity strength and endurance training on hormonal and skeletal muscle adaptations. J. Appl. Physiol. 78:976-989. 1995.

9. LALICH, R.A. An initiative to retain reserve soldiers failing to meet weight and physical fitness standards: The Wisconsin Army National Guard experience. Mil. Med. 166:204-207. 2001.

10. LegG, S.J., AND A. DugGan. The effects of basic training on aerobic fitness and muscular strength and endurance of British Army recruits. Ergonomics 39:1403-1418. 1996.
11. McCaig, R.H., AND C.Y. Gooderson. Ergonomic and physiological aspects of military operations in a cold wet climate. $E r$ gonomics 29:849-857. 1986.

12. Mello, R.P., B.C. Nindl, M.A. SharP, V.J. Rice, R.K. Bills, AND J.F. PATTON. Predicting lift and carry performance from muscular strength, anaerobic power and body composition variables. Med. Sci. Sports Exerc. 27(Suppl.):S152. 1995.

13. North Atlantic Treaty Organization. NATO Defence Research Group: Final Report and Resource Manual on Military Physical Training. Technical Report AC/243(Panel 8)TR/16. Brussels: North Atlantic Treaty Organization, 1994.

14. Patton, J.F., W.L. Daniels, AND J.A. Vogel. Aerobic power and body fat of men and women during army basic training. Aviat. Space Environ. Med. 51:492-496. 1980.

15. Powell, G.D., D. Dumitru, AND J.J. Kennedy. The effect of command emphasis and monthly physical training on Army physical fitness scores in a National Guard unit. Mil. Med. 158: 294-297. 1993.

16. RAmsbottom, R., J. Brewer, AND C. Williams. A progressive shuttle run test to estimate maximal oxygen uptake. Br. J. Sports Med. 22:141-144. 1988.

17. Rayson, M., D. Holliman, and A. Belyavin. Development of physical selection procedures for the British Army. Phase 2: Relationship between physical performance tests and criterion tasks. Ergonomics 43:73-105. 2000.

18. RAYson, M.P. The development of physical selection procedures. Phase 1: Job analysis. In: Contemporary Ergonomics 1998. M.A. Hanson, ed. London: Taylor and Francis, 1998. pp. 393-397.

19. Rice, V.J., AND M.A. Sharp. Prediction of performance on two stretcher-carry tasks. Work 4:201-210. 1994.

20. Rosendal, L., H. Langberg, A. SKov-Jensen, And M. KJaer. Incidence of injury and physical performance adaptations during military training. Clin. J. Sport Med. 13:157-163. 2003.

21. Sharp, M.A., J.F. Patton, J.J. KnapiK, K. Hauret, R.P. MelLO, M. Ito, AND P.N. FRYKMAN. Comparison of the physical fitness of men and women entering the U.S. Army: 1978-1998. Med. Sci. Sports Exerc. 34:356-363. 2002.

22. Vogel, J.A., J.P. Crowdy, A.F. Amor, AND D.E. Worsley Changes in aerobic fitness and body fat during army recruit training. Eur. J. Appl. Physiol. 40:37-43. 1978.

23. Williams, A.G., M.P. RAYSON, AND D.A. JonEs. Effects of basic training on material handling ability and physical fitness of British Army recruits. Ergonomics 42:1114-1124. 1999.

24. Williams, A.G., M.P. Rayson, AND D.A. Jones. Resistance training and the enhancement of the gains in material-handling ability and physical fitness of British Army recruits during basic training. Ergonomics 45:267-279. 2002.

25. Williams, A.G., M.P. Rayson, and D.A. Jones. Training diagnosis for a load carriage task. J. Strength Cond. Res. 18:3034. 2004.

\section{Acknowledgments}

Gratitude is expressed for the cooperation of military staff and recruits and of the Ministry of Defence and for the assistance of Marc Hopkin-Taylor.

Address correspondence to Dr. Alun G. Williams, a.g. williams@mmu.ac.uk. 